\title{
DIGITAL MARKETING SEBAGAI STRATEGI KOMUNIKASI PEMASARAN "WAROENK ORA UMUM" DALAM MENINGKATKAN JUMLAH KONSUMEN
}

\author{
Ascharisa Mettasatya Afrilia ${ }^{1}$ \\ ${ }^{1}$ Pogram Studi Ilmu Komunikasi, Universitas Tidar \\ Jalan Kapten Suparman No. 39, Potrobangsan, Magelang Utara. \\ E-mail: mettaafrilia@untidar.ac.id
}

Diterima : 31 Januari 2018

Disetujui : 15 Februari 2018

Diterbitkan : 28 Februari 2018

\begin{abstract}
Abstrak
Purwokerto adalah ibukota Kabupaten Banyumas yang terus tumbuh dan berkembang. Purwokerto telah mengalami transformasi kependudukan baik dari segi kuantitas maupun kualitas. Berdasarkan data statistik dapat diketahui bahwa jumlah penduduk di kota tersebut per tahun 2014 berkisar antara 292.782 jiwa dengan luas wilayah 38,58 KM². Pertambahan penduduk per tahun juga semakin meningkat ditambah dengan jumlah penduduk pendatang. Hal tersebut merupakan peluang bagi para pelaku bisnis tidak terkecuali pada bisnis kuliner. Waroenk Ora Umum (WOA) adalah salah satu jenis usaha bidang kuliner yang cukup pesat pertumbuhannya di kota Purwokerto. Seiring dengan era milenal saat ini, perlu ditelaah lebih jauh strategi komunikasi pemasaran yang tepat sasaran. Dan digital marketing merupakan salah satu strategi yang cukup berdampak untuk meningkatkan jumlah konsumen bidang usaha kuliner di era seperti sekarang ini. Penelitian ini menggunakan metode penelitian kualitatif. Pengumpulan data dilakukan dengan cara observasi, dokumentasi, dan wawancara. Hasil menunjukkan bahwa Waroenk Ora Umum Purwokerto telah memanfaatkan strategi digital marketing yang juga diimbangi dengan strategi pemasaran lainnya.
\end{abstract}

Kata Kunci: Digital Marketing, Komunikasi Pemasaran, Bisnis Kuliner.

\begin{abstract}
Purwokerto is the capital of Banyumas Regency as a growing and developing small tow. Purwokerto has experienced population transformation in terms of both quantity and quality. Based on statistical data can be seen that the population in the city per year 2014 ranged between 292,782 people with an area of $38.58 \mathrm{KM}^{2}$. The increase of population per year is also increasing along with the number of migrant population. This is an opportunity for business people are no exception to the culinary business. Waroenk Ora Umum is one type of culinary business which is quite rapid growth in the city of Purwokerto. Along with the current milenal era, it is necessary to further explore the marketing strategy of targeted marketing communications. And digital marketing is one strategy that has enough impact to increase the number of consumer culinary business in this era. This study used qualitative research methods. Data collection is done by observation, documentation, and interview. The results show that Waroenk Ora Umum Purwokerto has utilized digital marketing strategy which is also balanced with other marketing strategies.
\end{abstract}

Keywords: Digital Marketing, Marketing Communication, Culinary Business. 


\section{PENDAHULUAN}

Purwokerto adalah ibu kota Kabupaten Banyumas yang terus tumbuh dan berkembang. Purwokerto telah mengalami transformasi kependudukan baik dari segi kuantitas maupun kualitas. Berdasarkan data statistik pada Banyumas dalam Angka, dapat diketahui bahwa jumlah penduduk di kota tersebut per tahun 2014 berkisar antara 292.782 jiwa dengan luas wilayah $38,58 \mathrm{KM}^{2}$. Pertambahan penduduk per tahun juga semakin meningkat ditambah dengan jumlah penduduk pendatang.

Secara tradisional, Purwokerto bukan merupakan kota industri maupun perdagangan. Hingga saat ini, aktivitas industri masih jarang ditemukan di kota ini. Padahal Purwokerto merupakan daerah potensial yang strategis untuk melakukan investasi dengan lahan yang masih tersedia luas, akses menuju kota besar lainnya yang mudah, serta tenaga kerja profesional yang tersedia. Kota ini dapat dikatakan tidak memiliki industri dalam skala besar yang dapat menyerap ribuan tenaga kerja atau mencakup wilayah puluhan hektare. Singkatnya, kota ini sama sekali bukan kota industri maupun perdagangan (www.wikipedia.com).

Pergolakan bidang ekonomi di Purwokerto mulai terasa pada awal tahun 2000. Perubahan signifikan terjadi ketika Purwokerto mulai dibanjiri oleh mahasiswa-mahasiswa dari berbagai kota baik dari Pulau Jawa maupun luar Pulau Jawa. Satu universitas negeri dan dua universitas swasta yang ada saat itu, menjadi magnet bagi para pendatang untuk meramaikan kota Purwokerto.

Sejak saat itu, aktivitas ekonomi rakyat yang berkenaan dengan kebutuhan mahasiswa pun menggeliat. Ribuan kamar kos dibangun untuk disewakan bagi mahasiswa pendatang. Kios-kios alat tulis bermunculan. Bahkan, jasa pencucian baju (laundry) pun tidak kalah ramai. Bukan hanya itu, ratusan tempat makan juga mulai didirikan untuk melayani kebutuhan lambung para mahasasiswa (www.wikipedia.com). Kondisi semacam itu membuat perekonomian kota Purwokerto tumbuh cukup signifikan sebagai kota jasa. Geliat tersebut tentu menjadi peluang pasar yang sangat besar bagi para pelaku bisnis.

Bertambahnya pendatang khususnya mahasiswa di Purwokerto, telah membuka peluang bisnis baru di kota ini, salah satunya adalah bisnis kuliner. Waroenk Ora Umum (WOU) merupakan salah satu bentuk usaha yang bergerak di bidang jasa kuliner dan tergolong baru di kota Purwokerto. Meski belum lama berdiri yakni pada tahun 2016, namun WOU telah memiliki target market yang cukup luas.

Berdasarkan data yang terkumpul, dapat diketahui bahwa pengambilan nama Waroenk Ora Umum terinspirasi dari usaha sejenis di bidang kuliner yakni Warung Upnormal. Mengusung tema yang tidak biasa, WOU mencoba untuk mengaplikasikan budaya daerah Purwokerto sebagai lokasi berdirinya kafe tersebut.

Purwokerto yang secara geografi terletak di wilayah Jawa Tengah memiliki bahasa daerah Jawa dengan dialek Banyumasan atau lebih dikenal dengan istilah "ngapak". Bahasa ini merupakan bahasa daerah yang patut untuk dilestarikan dan dihargai (www.wikipedia.com). Dialeknya sendiri menjadi ciri yang khas dan menambah keragaman budaya daerah di Indonesia.

Berdasarkan makna harfiahnya merujuk pada bahasa Jawa Banyumasan, kata "ora umum" itu sendiri memiliki arti "tidak biasa". Sementara secara filosofi, WOU bertujuan untuk menyuguhkan menu-menu makanan dan minuman yang tidak biasa, unik, dan khas. Atas dasar itulah, tagline "Waroenk Anti Mainstream" dipilih untuk menyesuaikan makna filosofis tersebut. 


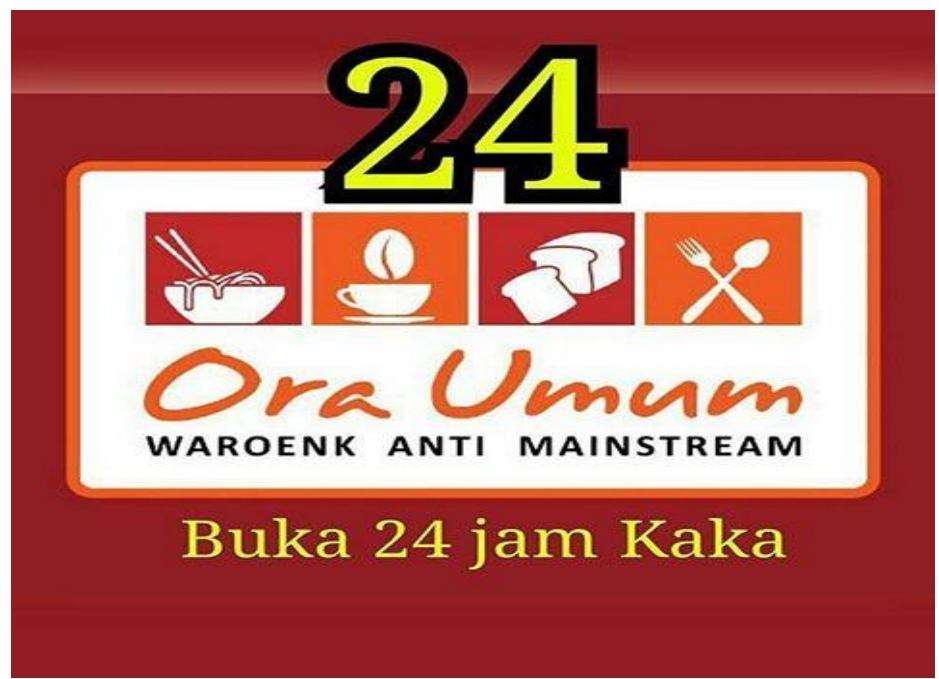

Gambar 1. Logo dan tagline Waroenk Ora Umum Sumber: Instagram Waroenk Ora Umum, 2017

Pelaku bisnis WOU membidik pasar kuliner karena melihat peluang kebetuhan bahan makan yang meningkat. Pada dasarnya, bidikan segmentasi WOU ditujukan untuk masyarakat secara umum, namun lebih mengerucut bagi masyarakat di range usia antara 1635 tahun. Dengan range usia tersebut, WOU memiliki peluang besar untuk menggarap lahan konsumen yang beragam. Oleh karena itu, pilihan menu yang disuguhkan pun disesuaikan dengan selera masyarakat di segmen usia tersebut.

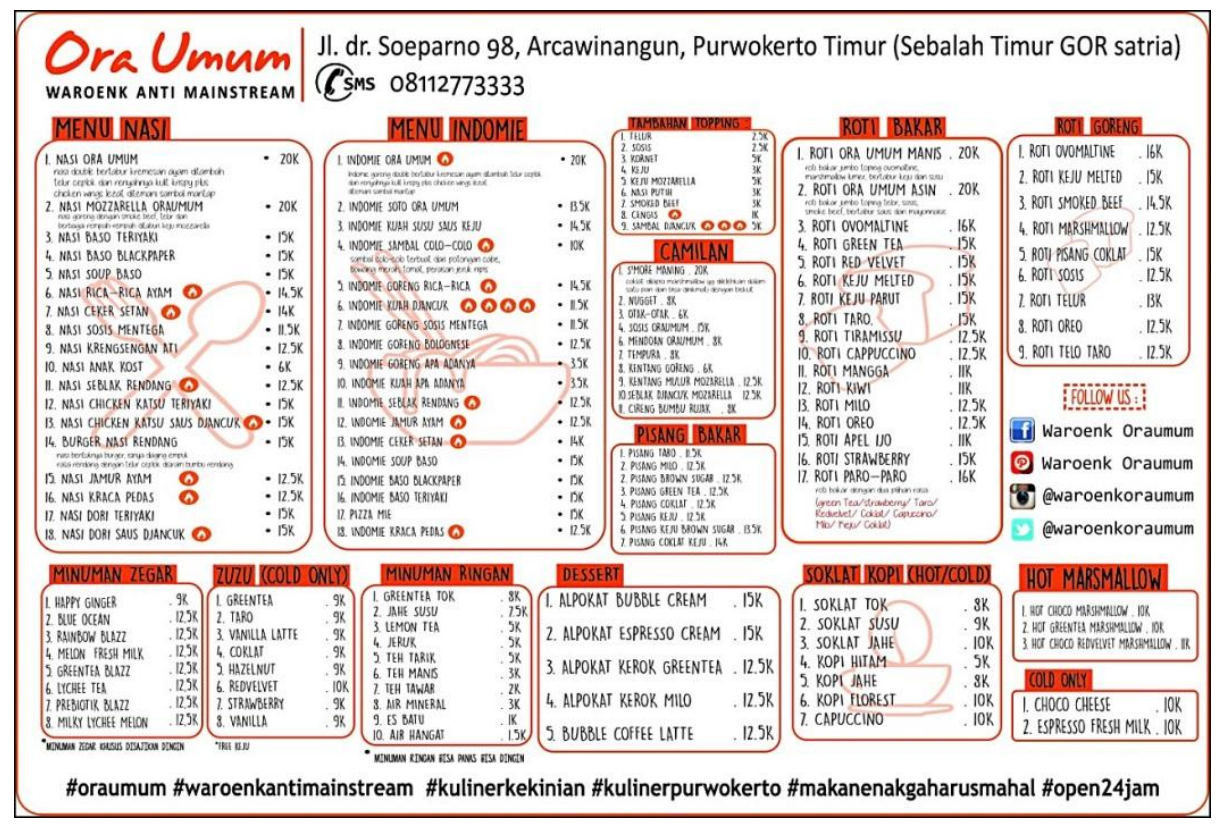

Gambar 2. Menu Waroenk Ora Umum

Sumber: Instagram Waroenk Ora Umum, 2017

Berdasarkan menu dan harga yang disuguhkan di atas, dapat diketahui bahwa WOU berusaha untuk melengkapi kebutuhan dasar pangan manusia dengan cara yang berbeda. WOU mencoba untuk melakukan kolaborasi makanan khas Purwokerto yang dikenal dengan mendoan Banyumasan dan Soto Sokaraja ke dalam menu mie instan yang familiar di 
kalangan remaja dan mahasiswa. Tidak hanya itu, menu masakan ' $a$-la bento dan makanan ringan seperti roti bakar serta camilan lainnya, juga disuguhkan untuk memenuhi kebutuhan pasar. Jenis minuman yang ditawarkan pun tidak kalah variatif. Mulai dari jenis minuman biasa seperti air mineral, aneka teh dan kopi, hingga jenis minuman yang dibuat dengan rasa dan tampilan yang lebih kekinian.

Secara umum, manajemen pemasaran WOU dapat dikatakan telah berlaku maksimal dan konsisten. Namun tentu saja target market yang digarap tidak serta merta dapat tercapai tanpa strategi pemasaran yang tepat. Strategi pemasaran merupakan hal mendasar yang perlu dilakukan oleh setiap para pelaku usaha baik yang bergerak di bidang penyedia barang maupun jasa. Strategi pemasaran perlu dilakukan karena setiap produk baik barang maupun jasa tidak dapat menemukan konsumennya sendiri, melainkan perlu melalui tahapan-tahapan yang terpola.

Pemasaran menurut American Marketing Association adalah proses perencanaan dan pelaksanaan rencana dalam hal penetapan harga, promosi, dan distribusi ide-ide, barangbarang dan jasa untuk menciptakan pertukaran yang memuasakan tujuan-tujuan individual dan organisasi.

Sedangkan strategi pemasaran menurut Kotler (2008:58) adalah logika pemasaran yang digunakan oleh perusahaan dengan harapan agar unit bisnis dapat mencapai tujuan perusahaan. Menurut Radiosunu (2001: 27), strategi pemasaran didasarkan atas lima konsep strategi berikut:

a. Segmentasi pasar.

Tiap pasar terdiri dari bermacam-macam pembeli yang mempunyai kebutuhan, kebiasaan membeli dan reaksi yang berbeda-beda. Perusahaan tak mungkin dapat memenuhi kebutuhan semua pembeli. Karena itu perusahaan harus mengkelompokkelompokkan pasar yang bersifat heterogen ke dalam satuan-satuan pasar yang bersifat homogen

b. Market positioning.

Perusahaan tak mungkin dapat menguasai pasar keseluruhan. Maka prinsip strategi pemasaran kedua adalah memilih pola spesifik pemusatan pasar yang akan memberikan kesempatan maksimum kepada perusahaan untuk mendapatkan kedudukan yang kuat. Dengan kata lain perusahaan harus memilih segmen pasar yang dapat menghasilkan penjualan dan laba yang paling besar.

c. Targeting.

Targeting adalah strategi memasuki segmen pasar yang dijadikan sasaran penjualan.

d. Marketing mix strategy.

Kumpulan variabel-variabel yang dapat digunakan perusahaan untuk mempengaruhi tanggapan konsumen. Variabel-variabel yang dapat mempengaruhi pembeli adalah variabelvariabel yang berhubungan dengan product, place, promotion dan price (4P).

e. Timing strategy.

Penentuan saat yang tepat dalam memasarkan produk merupakan hal yang peru diperhatikan. Meskipun perusahaan melihat adanya kesempatan baik. Terlebih dulu harus dilakukan persiapan baik produksi.

Melihat peluang bisnis kuliner di Purwokerto yang begitu besar, perlu disadari bahwa demi mendapatkan tempat di mata konsumen, perlu dilakukan strategi marketing yang tepat. Mengingat semakin banyaknya bisnis kuliner baru di kota tersebut yang memberikan penawaran beragam, menjadikan persaingan bisnis kuliner di Purwokerto begitu ketat. Terlebih di era seperti sekarang ini yang mengedepankan nilai-nilai digitalisasi, perlu diterapkan pula strategi pemasaran berbasis digital marketing agar dapat mencapai tujuan 
dengan cara yang lebih cepat dan tepat. Merujuk pada paparan tersebut maka penelitian ini dilakukan untuk mengatahui bagaimana digital marketing sebagai strategi pemasaran yang diterapkan oleh Waroenk Ora Umum (WOU) dalam meningkatkan jumlah konsumen.

\section{METODE PENELITIAN}

Metode penelitian yang digunakan dalam riset ini adalah metode penelitian kualitatif deskriptif. Metode tersebut dipilih guna menjawab pertanyaan riset yang bertujuan untuk mengetahui bagaimana penerapan digital marketing sebagai strategi pemasaran Waroenk Ora Umum untuk meningkatkan jumlah konsumen. Metode deskripitf kualitatif adalah suatu penelitian yang menghasilkan data yang bersifat deskriptif (penggambaran) berupa fakta-fakta yang tertulis maupun lisan dari perilaku yang dicermati, dalam keadaaan yang berlangsung secara wajar dan ilmiah dan bukan dalam kondisi yang terkendali (Sanafiah, 2005:18). Oleh karena itu, metode kualitatif deskriptif diharapkan mampu menjabarkan unsur-unsur yang ada dalam strategi pemasaran Waroenk Ora Umum secara mendalam.

Data-data yang digunakan berasal dari hasil wawancara, observasi, dan pengumpulan informasi serta dokumen yang berkaitan dengan konteks penelitian ini. Data yang diperoleh kemudian diolah berdasarkan pemilihan dan pemilahan agar terjaring mana yang tepat untuk menjabarkan masalah sesuai dengan tujuan penelitian.

Sementara itu, validitas data dilakukan berdasarkan teknik triangulasi. Triangulasi merupakan cara terbaik untuk menghilangkan perbedaan-perbedaan konstruksi, kenyataan yang ada dalam konteks suatu studi sewaktu mengumpulkan data mengenai berbagai kejadian dan hubungan dari berbagai pandangan, dengan kata lain peneliti me-recheck temuannya dengan jalan membandingkannya dengan berbagai sumber, metode atau teori (Moleong, 2004:332).

\section{HASIL DAN PEMBAHASAN}

\section{Pemetaan Strategi Pemasaran Waroenk Ora Umum}

Komunikasi pemasaran sagat berhubungan erat dengan karakter dan perilaku masyarakat secara luas. Sebagian besar lingkungan masyarakat memiliki kebutuhan dan tren yang berbeda-beda (Patrick dalam Suwatno, 2017:57). Oleh karena itu, tugas utama dari rencana komunikasi pemasaran adalah melakukan identifikasi terhadap kelompok pasar yang berbeda-beda tersebut. Proses identifikasi pasar dilakukan dengan cara melakukan pemetaan strategis yang menandung 3 elemen utama, yaitu Segmenting, Targeting, dan Positioning (STP).

\section{Segmentation Waroenk Ora Umum}

Segmentasi pasar merupakan proses pembagian konsumen ke dalam profil segmen yang berbeda-beda. Segmentasi dapat dilakukan berdasarkan beberapa kategori, namun yang paling sering digunakan adalah demografi, geografi, psikografi, dan behavioral (Suwatno, 2017:60).

Berdasarkan kategori pada segmentasi pasar di atas, dapat dianalisis bahwa segmentasi pasar yang dilakukan oleh WOU berdasar pada segementasi demografi. Segementasi demografi tersebut berdasarkan pada kualifikasi gender (jenis kelamin), age (usia), social-economy (status sosial-ekonomi), dan educations level (jenjang pendidikan).

Jika dijabarkan, penerapan segmentasi pasar WOU menyasar usia antara 16-35 tahun. Sementara ditilik dari kategori gender, WOU menyasar target jenis kelamin laki-laki dan perempuan. Dengan menerapkan jam layanan 24 jam non stop, sasaran berdasarkan gender lebih condong ke jenis kelamin laki-laki di malam hari dengan asumsi bahwa konsumen 
laki-laki lebih memungkinkan untuk menghabiskan waktu untuk 'nongkrong' di WOU pada malam hingga dini hari. Sementara sasaran jenis kelamin perempuan lebih banyak ditargetkan di siang hingga malam hari.

Sedangkan dari status sosial ekonomi, segmentasi pasar WOU adalah kelas sosial menengah. Hal tersebut dapat dilihat dari harga yang dibandrol cukup murah dibanding dengan menu sejenis di café lain yang membandrol dengan harga jauh lebih mahal. Segmentasi tersebut juga dapat dilihat dari kalimat yang dijadikan template dalam setiap postingan manajemen WOU di akun media sosial mereka yakni "Makan enak di WOU, pas di mulut, pas di kantong”. Pada kalimat tersebut, menunjukkan bahwa makanan yang beraneka ragam di WOU sangat sesuai dengan selara untuk dinikmati di mulut sekaligus sesuai dengan harga yang terjangkau.

Sementara dari sisi status pendidikan, WOU menyasar konsumen dengan latar belakang pendidikan sejajar dengan SMA dan mahasiswa. Terlebih lagi dengan lokasi WOU yang memang berada di sekitar kampus Universitas Jendral Soedirman (UNSOED), Purwokerto. Hal tersebut menjadi keuntungan tersendiri bagi WOU untuk dapat menjaring konsumen dari sekitar kampus. Oleh karena itu juga, menu-menu yang ditawarkan oleh WOU disesuaikan dengan segmentasi pasarnya. Tidak heran manakala WOU menyuguhkan menu makanan dan minuman yang kekinian dan cukup hits di kalangan konsumennya.

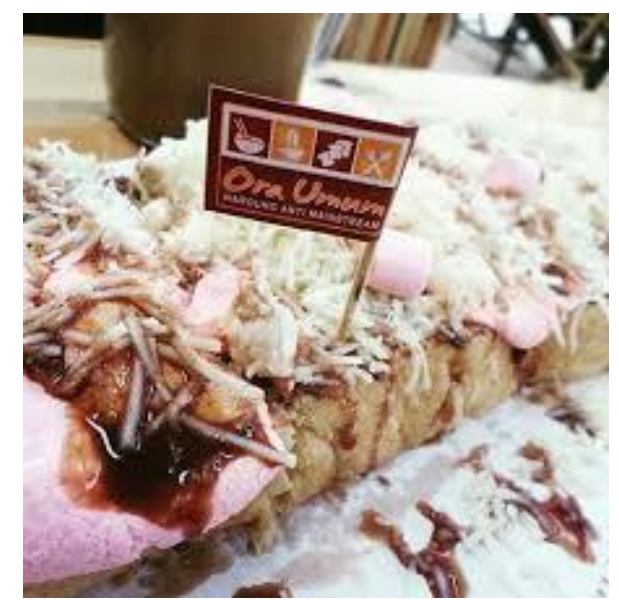

Gambar 3. Roti bakar keju Nutella dan Marsmellow Sumber: Instagram @ waroenkoraumum, 2017.

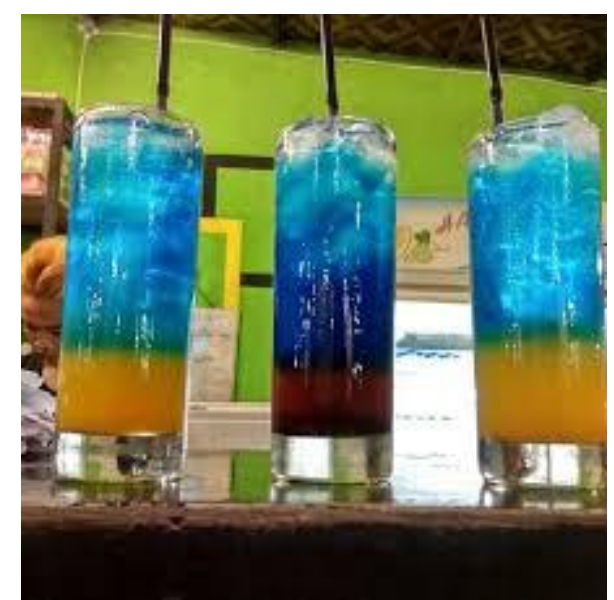

Gambar 4. Ocean Blue Drink

Sumber: Instagram @waroenkoraumum, 2017. 


\section{Targeting Waroenk Ora Umum}

Strategi targeting sangat penting dirumuskan sejak awal sebelum program pemasaran dilaksanakan. Para marketer diharuskan memiliki analisis dan feeling yang tajam untuk menentukan target. Pada prinsipnya, targeting harus ditentukan secara jelas dan tegas, tidak mengambang apalagi bimbang (Suwatno, 2017:66).

Menurut Patrick De Pelsmacker (2013:67), ada beberapa tipe dasar dari strategi targeting, antara lain:

\section{Concentration on one segment \\ 2. Selective specialization \\ 3. Product specialization \\ 4. Market specialization \\ 5. Full market coverage}

Merujuk pada tipe dasar tersebut, WOU merupakan bidang bisnis yang berada pada wilayah market specialization. Pada tipe ini, perusahaan yang dalam hal ini adalah WOU, lebih fokus kepada salah satu segmen dan menjual produk yang beraneka ragam kepada kelompok konsumen tersebut. Produk yang dimaksud adalah aneka makanan dan minuman yang ditawarkan oleh WOU untuk menyasar target market sesuai dengan segementasinya.

Penentuan targeting tidak dapat dilakukan secara sembarangan. Secara teknis, proses tersebut dapat dilakukan dengan pendekatan outside-in. Pendekatan tersebut berangkat dari fakta dan data real yang diperoleh dari lapangan. Hal ini penting karena pendekatan insideout lebih berpijak pada asumsi dan analisis logika tanpa referensi data lapangan yang cukup sehingga masih diragukan ketepatan dan akurasinya (Suwatno, 2017:68).

\section{Positioning Waroenk Ora Umum}

Strategi positioning tidak kalah penting karena ia menegaskan posisi brand atau produk di antara brand yang lain. Ia berfungsi untuk membedakan dirinya ada pada pikiran konsumen. Positioning harus jelas sehingga dapat membuat konsumen memosisikan brand tertentu pada skema asosiasi tertentu. Pada kasus ini, WOU memosisikan dirinya sebagai tempat makan yang tidak hanya menawarkan kebutuhan pangan namun juga menyediakan kenyamanan dan ketepatan harga.

WOU memahami posisinya yang juga dapat dikatakan masuk dalam kategori yang sama dengan Warung Upnormal. Menjadi hal yang berbeda ketika WOU memutuskan untuk lebih memberikan keragaman menu. Berbeda dengan Warung Upnormal yang sudah identik dengan menu-menu mi instan dengan berbagai variasi rasa dan isian. Tidak hanya itu, WOU juga memahami betul posisinya yang siap untuk konsisten dengan strategi positioning yang dipilihnya tersebut.

\section{Digital Marketing Waroenk Ora Umum}

Dunia digital diprediksi akan menjadi poin krusial bagi seluruh aktivitas manusia termasuk aktivitas bisnis. Hal tersebut dapat terlihat dari beberapa indikator berupa naiknya pengeluaran iklan digital, kepemilikan smartphone untuk mengakses internet yang semakin meningkat, perbaikan infrastruktur telekomunikasi dalam rangka peningkatan kualitas akses data, serta diluncurkannya layanan 4G. Pesatnya perkembangan teknologi, dunia digital dan internet tentu juga berimbas pada dunia pemasaran.

Revolusi teknologi informasi telah mengubah lanskap dunia pemasaran dalam beberapa tahun terakhir ini. Metode komunikasi pemasaran yang sebelumnya bersifat tradisional dan konvensional, kini telah terintegrasi dalam dunia digital (Suwatno, 2017:99). 
Pertemuan antara penjual dan pembeli tidak lagi harus dilakukan secara nyata, namun transaksi jual beli sudah dapat dilakukan di dunia maya tanpa harus bertatap muka.

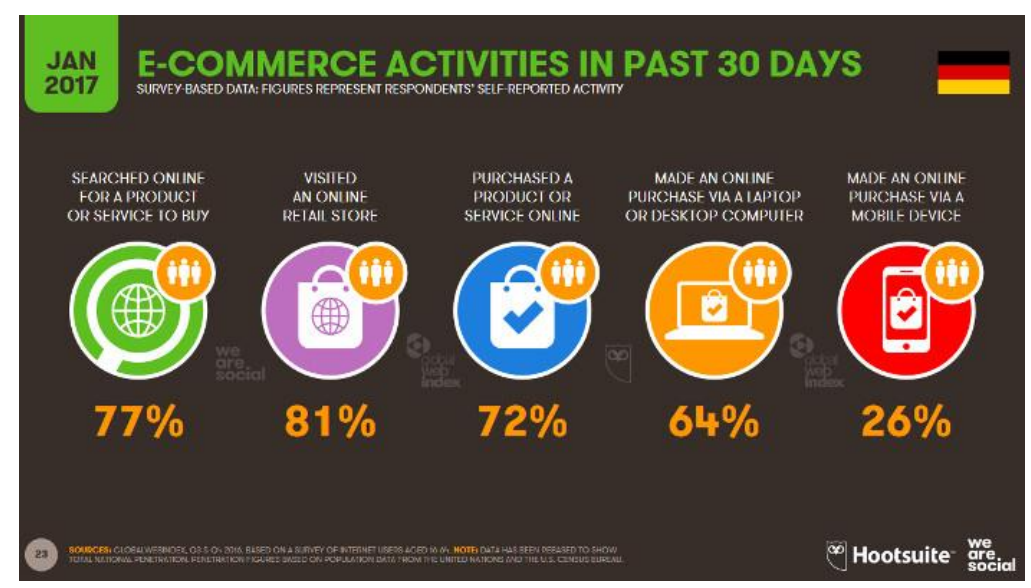

Gambar 5. Aktivitas Belanja Online

Sumber: https://socialmediaagency.one/agency/

Berdasarkan data di atas, dapat dilihat peningkatan aktivitas jual beli secara digital yang begitu signifikan. Signifikansi tersebut tejadi karena digital marketing dinilai lebih prospektif untuk memungkinkan para calon pelanggan potensial dalam memperoleh segala macam informasi mengenai produk dan bertransaksi melalui internet.

Di satu sisi, digital marketing memudahkan pebisnis memantau dan menyediakan segala kebutuhan dan keinginan calon konsumen. Di sisi lain, calon konsumen juga dapat mencari dan mendapatkan informasi produk hanya dengan menjelajah dunia maya. Dengan kata lain, digital marketing dapat menjangkau seluruh masyarakat di manapun mereka berada tanpa batasan ruang dan waktu.

Hal tersebut begitu disadari oleh pelaku bisnis WOU. Terlihat dari pemanfaatan digital marketing yang mereka lakukan sebagai bentuk strategi marketing untuk meningkatkan jumlah konsumen dan loyalitas. Dalam hal ini, pihak WOU secara sadar telah memosisikan diri dengan menentukan pilihan sarana digital marketing yang mereka terapkan.

Sementara itu, berdasarkan data yang dilansir oleh We are Social, sebuah agensi digital marketing di Amerika menyebutkan bahwa platform media sosial yang paling banyak digunakan di Indonesia per Januari 2017 adalah Youtube (49\%) dan Facebook (48\%). Posisi ketiga dan seterusnya ditempati oleh Instagram (39\%), Twitter 38\%), Whatsapp (38\%), dan Google (36\%). Sisanya ditempati secara berurutan oleh FB Messenger, Line, Linkedin, BBM, Pinterest, dan Wechat. 


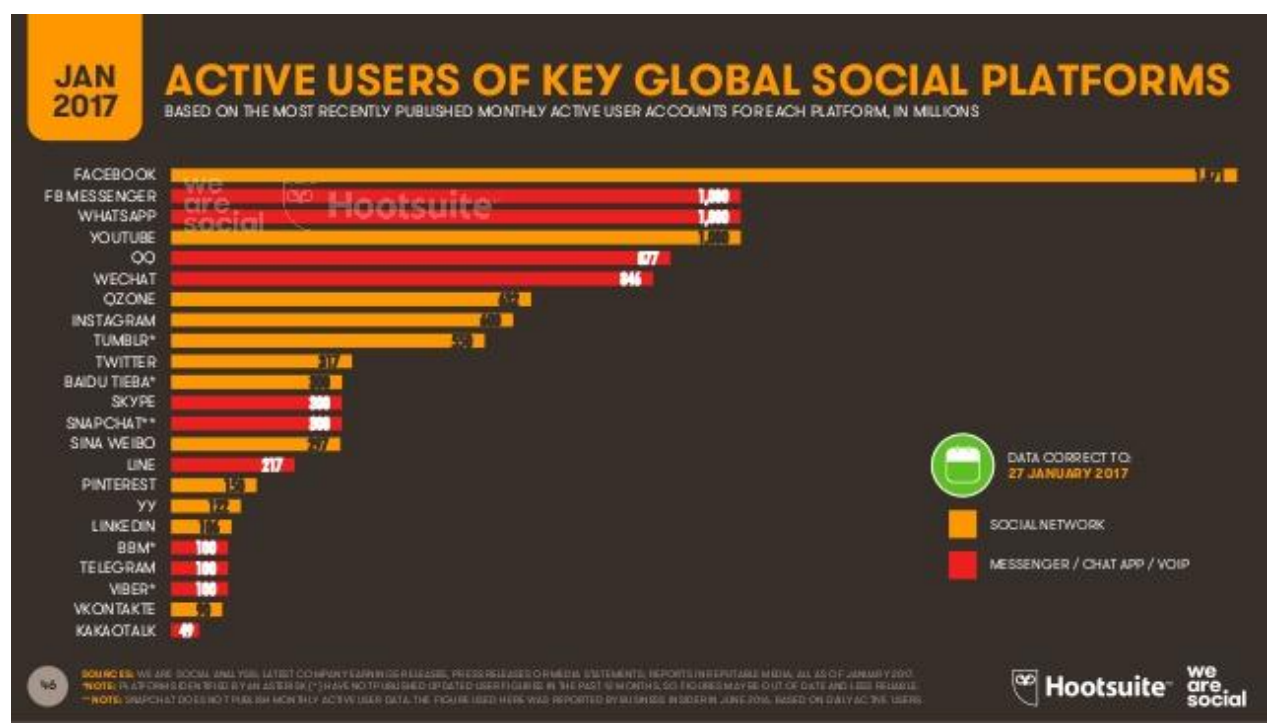

Gambar 6. Platform Media Sosial yang Paling Sering Digunakan di Indonesia Sumber: https://www.slideshare.net/wearesocialsg/digital-in-2017-global-overview

Manajemen WOU berusaha untuk memanfaatkan digital marketing secara maksimal. Menyadari bahwa beberapa tahun terakhir ini sosial media Instagram begitu banyak digandrungi masyarakat Indonesia, maka pihak WOU pun memanfaatkan Instagram sebagai media marketing mereka. Akun Instagram milik WOU yakni @waroenkoraumum dapat dikatakan telah berhasil dikelola dengan baik oleh pihak manajemen WOU. Terbukti dengan jumlah follower yang semakin bertambah dan antusiasme para follower terhadap hal-hal yang diposting oleh tim WOU.

Kirim Pesan
kiriman
17,9k

Gambar 7. Akun Instagram dan Jumlah Follower Waroenk Ora Umum Sumber: Instagram @waronekoraumum, 2017.

Berdasarkan tampilan Instagram WOU di atas, dapat diketahui bahwa jumlah follower mencapai 16,9 ribu follower. Jumlah yang tidak sedikit dan dibutuhkan pengelolaan 
yang baik untuk mencapai jumlah sebanyak itu. Meski di sisi lain tersedia jasa layanan penambah jumlah follower untuk akun Instagram, namun WOU mencapai jumlah tersebut dengan kekuatan loyalitas dari para konsumennya. Baik konsumen potensial maupun non potensial. Hal tersebut dapat dilihat dari respon follower yang cukup antusias pada kolom komentar pada setiap gambar yang diposting oleh tim WOU.

Manajemen WOU secara sadar memahami betul peran media sosial sebagai salah satu media digital marketing yang perlu untuk dikelola dengan maksimal. Bukan sekedar akun yang dibuat dengan asal-asalan. Namun lebih dari itu, akun tersebut perlu dikelola mulai dari hal apa yang akan diposting, pesan apa saja yang perlu untuk disampaikan, kapan waktu yang tepat untuk memposinting, dan lain sebagainya.

Seperti yang dinyatakan oleh Rob Stokes (2008:30-31) bahwa dalam menjalankan komunikasi pemasaran digital, marketer harus memiliki taktik sehingga menghasilkan dampak (impact) yang efektif dan maksimal terhadap penjualan produk. Beberapa taktik tersebut antara lain taktik dalam pengelolaan media sosial. Rob Stokes mengatakan bahwa taktik dalam media sosial also known as consumer-generated media, is media (in the form of text, visuals and audio) created to be shared. It has changed the face of marketing by allowing collaboration and connection in a way that no other channel has been able to offer. Sementara itu, Rob Stokes melanjutkan bahwa ada outcome khusus dari taktik dalam media sosial yaitu branding, values creation, and participation.

Berdasarkan hal tersebut, pemanfaatan digital marketing oleh WOU sebagai marketer dapat dikatakan sudah maksimal. WOU melakukan kolaborasi secara signifikan untuk melempar pesan dalam bentuk gambar, audio-visual, maupun pesan text dengan tepat. Bahkan kolaborasi dan parsisipasi konsumen juga telah diikutsertakan oleh pihak WOU dalam setiap event yang diselenggarakan. Seperti tampak pada posting-an akun Instagram WOU berikut ini:

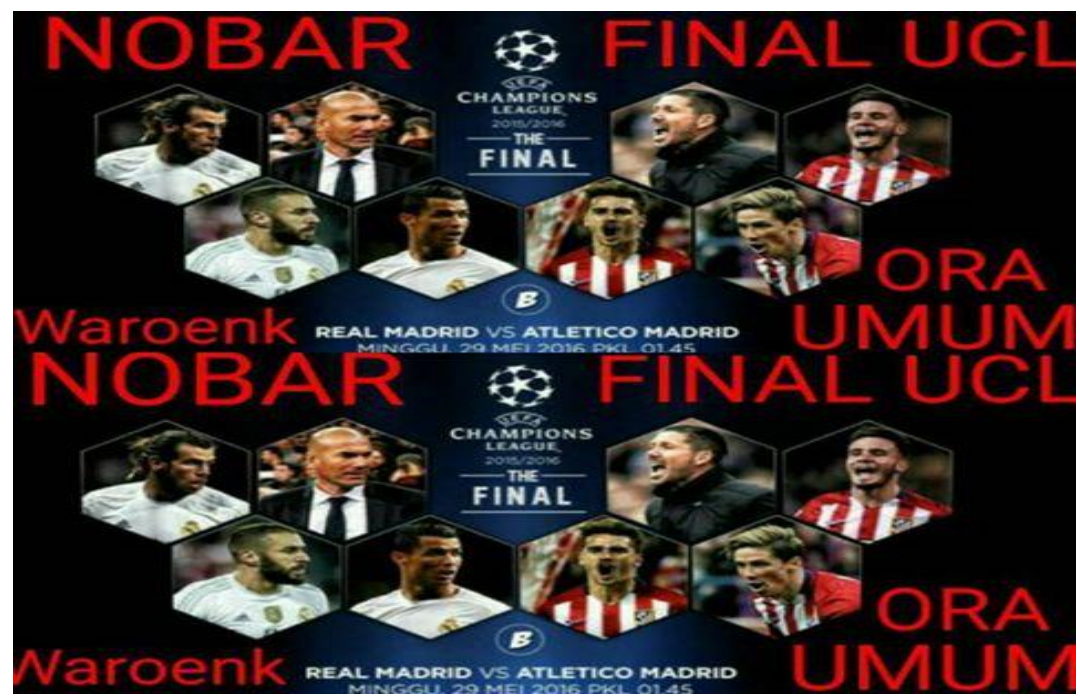

Gambar 8. Ajakan nonton bareng untuk semua konsumen WOU Sumber: Instagram @Waroenkoraumum, 2017.

Pada postingan di atas, dapat diketahui bahwa WOU mengikutsertakan khalayaknya baik konsumen potensial maupun nonpotensial untuk terlibat dalam event yang diselenggarakan oleh WOU. Hal tersebut tentu menjadi hal yang menarik dalam strategi pemasaran untuk mendapat perhatian dari para konsumennya. 


\section{SIMPULAN}

Strategi pemasaran yang diterapkan oleh manajemen Waroenk Ora Umum (WOU) dapat dikatakan cukup stabil dan maksimal. Hal tersebut dapat dilihat dari tahap STP (Segmentation, Targeting, dan Positioning) yang diterapkan oleh pihak WOU. Selain itu, strategi pemasaran WOU juga telah memanfaatkan media sosial sebagai sarana dalam proses digital marketing yang mereka lakukan.

Media sosial merupakan sarana digital marketing yang paling mudah untuk dimanfaatkan. Media sosial dapat dikatakan sebagai gerbang pembuka sebuah usaha untuk meluncur di dunia maya untuk menjangkau lebih luas target market yang sulit dijangkau dalam dunia nyata. Efek kecepatan dalam penyebaran informasi merupakan salah keunggunalan yang dapat diperoleh dengan memanfaatkan media sosial. Tidak hanya itu, hal-hal yang disampaikan melalui media sosial juga memiliki kekuatan yang 'shareable' dengan mudah. Bahkan feedback dari khalayak juga dapat dengan segera dilihat serta dianalisis untuk kemajuan market yang bersangkutan.

Kemudahan tersebut tentu dapa menjadi stimulan bagi perkembangan kewirausahawanan dan keberlangsungan pasar kecil dan menengah termasuk bisnis kuliner WOU. Selain biaya yang murah dan tidak perlu keahlian khusus dalam melakukan inisiasi awal, media sosial dianggap mampu untuk secara langsung meraih (engage) calon konsumen. Oleh karena itu tidak heran bahwa pelaku usaha justru lebih menitikberatkan pemanfaatan media sosial dibanding dengan pengembangan media digital lain seperti sebuah situs. Meski demikian, ketepatan dalam mengelola juga perlu dipertimbangkan, sehingga pesan dapat tepat sasaran dan sesuai dengan tujuan awal.

\section{REFERENSI}

Kotler, Philip. 2008. Manajemen Pemasaran Edisi 12 Jilid 2. Jakarta: Indeks Kotler 2008

Moleong, Lexy J. (2007) Metodologi Penelitian Kualitatif, Penerbit PT Remaja Rosdakarya Offset, Bandung (Moleong, 2004:332).

Patrick, Pelsmacker. 2013. Marketing Communication; A European Perspective. Harlow: Pearson.

Radiosunu. Manajemen Pemasaran; Suatu Pendekatan Analisis, Edisi Kedua, Universitas Gajah Mada, Yogyakarta, 2001

Sanapiah, Faisal. 2005. Format-format Penelitian Sosial. Rajawali Pers, Jakarta

Stokes, Rob. 2008. eMarketing; The Essential Guide to Marketing in A Digital World. Quirk eMarketing.

Suwatno. 2017. Komunikasi Pemasaran Kontekstual. Bandung: Simbiosa Rekatama Media.

Sumber lain:

www.wikipedia.com

www.instagram.com/waroenkoraumum/

Banyumas dalam angka

https://socialmediaagency.one/agency/

https://www.slideshare.net/wearesocialsg/digital-in-2017-global-overview

https://www.slideshare.net/wearesocialsg/digital-in-2017-global-overview 